\title{
ANALYSIS OF URIC ACID USING CARBON PASTE ELECTRODES MODIFIED BY MOLECULARLY IMPRINTED POLYMER AS POTENTIOMETRY SENSOR
}

\author{
H. Darmokoesoemo*, N. Widayanti, M. Khasanah and H.S. Kusuma* \\ Department of Chemistry, Faculty of Science and Technology, Airlangga University, \\ Surabaya-60115, Indonesia \\ *E-mail: handokodarmokoesoemo@gmail.com; heriseptyakusuma@gmail.com
}

\begin{abstract}
The development of carbon paste electrodes modified with the molecularly imprinted polymer (MIP) for the potentiometric analysis of uric acid was carried out in this study. MIP was made from methyl methacrylate as a monomer, ethylene glycol dimethacrylate as crosslinker, and uric acid as a template. The carbon paste electrodes/MIP is produced from carbon, MIP, and paraffin with ratio $40: 25: 35(\%, \mathrm{w} / \mathrm{w})$. The measurement of uric acid with carbon paste electrodes/MIP produced Nernst factor of $30.19 \mathrm{mV} /$ decade with a measurement range of $10^{-6}-10^{-3} \mathrm{M}$. The minimum detection limit of this method was $3.03 .10^{-6} \mathrm{M}$, the precision and accuracy towards uric acid with a concentration of $10^{-6}-10^{-3} \mathrm{M}$ was ranging between $1.36-2.03 \%$ and $63.9-166 \%$. The selectivity coefficient value was less than one which indicated that the electrode was selective against uric acid and was not interfered by urea. This electrode has a response time less than two minutes and lifetime is eight weeks with the usage is 104 times.
\end{abstract}

Keywords: carbon paste electrodes, molecularly imprinted polymer, potentiometric, uric acid.

(C) RASĀYAN. All rights reserved

\section{INTRODUCTION}

Potentiometric is an electrochemical method wherein a cell potential indicator electrode measured against the reference electrode at zero current. ${ }^{1}$ The potentiometric method has several advantages which are can be used for the determination of electroactive and non-electroactive compound, sample preparation, and the instrument operation is easy. Many potentiometric methods developed by researchers for the analysis of compounds whose presence in the body should always be controlled such as uric acid. Normal levels of uric acid in the blood of men that are in the range of 3.4 to $7.0 \mathrm{mg} / \mathrm{dL}$, while the woman is in the range from 2.4 to $5.7 \mathrm{mg} / \mathrm{dL} .^{2}$ In general, with increasing age, the levels of uric acid in the blood also increases. Uric acid levels that exceed normal limits in the body can cause various diseases including hyperuricemia, gout, leukemia, and pneumonia. ${ }^{3}$ Uric acid levels are very high levels can cause kidney damage, liver damage and cardiovascular disease. ${ }^{4}$ Controlling uric acid levels should be done early in order to do such a dangerous disease prevention.

In general, the methods used for the analysis of uric acid levels are colorimetric with chemical reagents or by enzymatic reactions. Chen et al. $(2005)^{4}$ analyzed the levels of uric acid in the blood by spectrophotometry using fosfotungstat acid reagent or enzyme uricase (uric oxidase). The analysis method of uric acid by spectrophotometry requires approximately 2-3 $\mathrm{mL}$ blood sample, have low sensitivity, and the detection limit is relatively high $(\mathrm{mM})$.

Another method that has been developed for the analysis of uric acid is high-performance liquid chromatography (HPLC). George et al. (2006) $)^{5}$ determined the levels of uric acid in the urine of cattle using HPLC method. From the research, the detection limit is low $\left(6.5 \times 10^{-7} \mathrm{M}\right)$ and the recovery is high. However, this method requires long analysis time, sample preparation is relatively complicated, and operational costs of instruments is expensive. In addition, uric acid can be analyzed using microwave-assisted extraction method. This method has the potential to be developed considering the time required for the analysis is very

Rasayan J. Chem., 10(1), 54-58(2017)

http://dx.doi.org/10.7324/RJC.2017.1011558 
fast. But in the analysis of urea, this method still needs to be validated using procedure that is relatively more complicated when compared with other methods such as potentiometry. 6,7

Therefore the aim of this research is can obtain the selective electrodes for measurement of uric acid with low levels by potentiometry. So that in this research used carbon paste electrodes/molecularly imprinted polymer as potentiometry sensor as an alternative method for the analysis of uric acid levels in body fluids.

\section{Materials and Chemicals}

\section{EXPERIMENTAL}

The materials used in this study is uric acid, methyl methacrylate, ethylene glycol dimethacrylate, benzoyl peroxide, chloroform, sodium hydroxide, glacial acetic acid, methanol, urea, carbon powder, silver wire, solid paraffin, hydrochloric acid, n-hexane, ethanol, and ammonium acetate. All chemicals used have purity degree of pro analysis (p.a). The water used is distilled water.

\section{Preparation of Carbon}

Carbon immersed in $\mathrm{HCl} 4 \mathrm{~N}$ for 24 hours, aided by stirring so that homogeneous, then do decantation and washing with distilled water and filtration using Buchner funnel. Carbon dried in an oven at temperature \pm $150^{\circ} \mathrm{C}$. Carbon that has dried soaked with n-hexane overnight. Then evaporated over a water bath and heated in a furnace for 2 hours at temperature $500^{\circ} \mathrm{C}$.

\section{Preparation of Poly Methyl Methacrylate (PMMA)}

Firstly, methyl methacrylate was weighed $0.1001 \mathrm{~g}$ and dissolved in $5 \mathrm{~mL}$ of chloroform and then heated. Next, ethylene glycol dimethacrylate (EGDMA) was weighed $0.9905 \mathrm{~g}$ and put into a glass beaker, then added with $0.1210 \mathrm{~g}$ benzoyl peroxide that was dissolved in chloroform $1 \mathrm{~mL}$. The solution mixture was heated at $60^{\circ} \mathrm{C}$ for \pm 2 hours without stirring. The next stage is drying in the open air and washing with ethanol three times. Then the dried solids heated in an oven to obtain a dry powder.

\section{Preparation of Non-Imprinted Polymer (NIP)}

NIP is made by mixing monomer, initiator, crosslinker and template with mole ratio of $1: 0.5: 5: 0.25{ }^{8}$ Methyl methacrylate monomer was weighed $0.1001 \mathrm{~g}$ and dissolved in $5 \mathrm{~mL}$ of chloroform. Uric acid was weighed $0.0420 \mathrm{~g}$ as a template and added to methyl methacrylate solution and allowed to stand for 1 hour. In a different glass, beaker inserted $0.9905 \mathrm{~g}$ EGDMA as cross-linker and $0.1210 \mathrm{~g}$ benzoyl peroxide as an initiator that has been diluted with $1 \mathrm{~mL}$ of chloroform. In the mixture of methyl methacrylate and uric acid is added to the mixture of crosslinker and initiator, then heated at $60^{\circ} \mathrm{C}$ without stirring to form solids. The solids that formed then dried in the open air. The solid was subsequently crushed and sieved with 200 mesh sieve size. NIP that has been formed is washed using a mixture of acetic acid and methanol in the ratio $1: 1$.

\section{Preparation of Molecularly Imprinted Polymer (MIP)}

MIP is obtained by extracting uric acid from half of the synthesized powders non-imprinted polymer (NIP) using $10 \mathrm{~mL}$ of ammonium acetate $1 \mathrm{M}$ (in ethanol, acetic acid, and water with a ratio of $40: 25: 35$ ) by centrifugation for $15 \mathrm{~min}$. The extraction is performed three times. The solids that formed was washed with water and then filtered and dried in an oven.

\section{Preparation of Carbon Paste Electrodes/Polymer (MIP or NIP or PMMA)}

Electrodes are made by filling three-quarter of the micropipette tube with molten paraffin in which has been installed Ag wire. Ag wire electrode serves as liaison with the potentiometer. The remaining portion of micropipette tube filled with a mixture consisting of solid paraffin, carbon, and polymer (MIP or NIP or PMMA) (0.105: $0.120: 0.075(\mathrm{~g}))$. The mixture previously had been heated to form a paste, then paste inserted into the remaining portion of the micropipette tube with emphasis to be solid and full filled. The electrode tip is rubbed with HVS paper to make smooth. Construction of carbon paste electrodes/polymer (MIP or NIP or PMMA) is shown in Figure-1. 


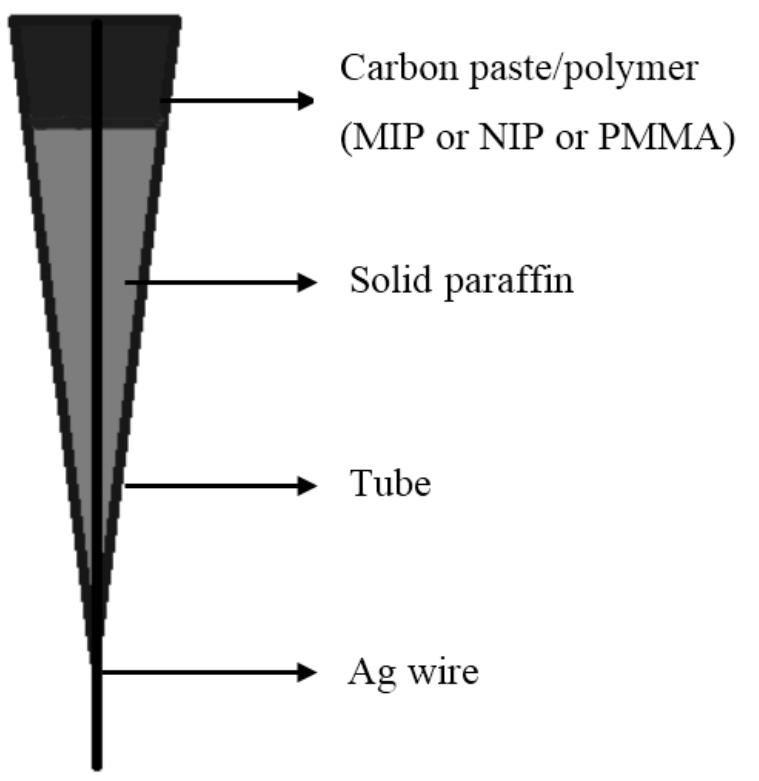

Fig.-1: Construction of carbon paste electrodes/polymer (MIP or NIP or PMMA)

The Comparison of Electrodes Performance Test

\section{RESULTS AND DISCUSSION}

In this research conducted the comparison of a performance test of electrode modified PMMA, NIP and MIP. This test is performed to determine the effect of uric acid mold in the MIP. The preparation of electrodes modified PMMA (EPMMA) and electrode modified NIP (ENIP) in accordance with the composition of an electrode modified MIP (EMIP) with composition carbon 0.120 grams, paraffin 0.105 grams, and MIP 0.075 gram. Furthermore, the three electrodes are used to measure the potential of uric acid solution $10^{-6}-10^{-3} \mathrm{M}$ that were conditioned at $\mathrm{pH}$ 5. From the measurement results of each electrode obtained Nernst factor value, measurement range, and linearity that can be seen in Table 1 and curve profile in Figure-2.

Table-1: The Nernst factor values, measurement range and linearity from measurement results of uric acid solution using EMIP, ENIP and EPMMA

\begin{tabular}{l|l|l|l|l|l|l}
\hline Electrodes & $\begin{array}{l}\text { Carbon } \\
(\%, w / w)\end{array}$ & $\begin{array}{l}\text { Polymer (MIP or } \\
\text { NIP or } \\
\text { PMMA })(\%, w / w)\end{array}$ & $\begin{array}{l}\text { Paraffin } \\
(\%, w / w)\end{array}$ & $\begin{array}{l}\text { Measurement } \\
\text { range }(\mathrm{M})\end{array}$ & $\begin{array}{l}\text { Nernst factor } \\
(\mathrm{mV} / \text { decade })\end{array}$ & $\begin{array}{l}\text { Linearity } \\
(r)\end{array}$ \\
\hline EMIP & 40 & 25 & 35 & $10^{-6}-10^{-3}$ & 27.02 & 0.9745 \\
\hline ENIP & 40 & 25 & 35 & $10^{-6}-10^{-3}$ & 20.60 & 0.9846 \\
\hline EPMMA & 40 & 25 & 35 & $10^{-6}-10^{-3}$ & 15.20 & 0.9907 \\
\hline
\end{tabular}

From Table-1 it is known that the Nernst factor value of EMIP is better than ENIP and EPMMA. This is because EMIP has the specific binding sites for the uric acid molecules. However, if viewed from the linearity value that expressed as the correlation coefficient ( $r$ ), EMIP has the correlation coefficient that is quite good, 0.9745. Based on the results in Table 1 show that EPMMA has better correlation coefficient than EMIP is equal to 0.9907, but EPMMA has Nernst factor that is far away from the theoretical value is $15.20 \mathrm{mV} /$ decade. 
RASĀYAN $J$. Chem.

Vol. 10 | No. 1 |54-58 | January - March | 2017

The Comparison of Potentiometric Method using Carbon Paste Electrodes/MIP with the Methods used in the Previous Study for Analysis of Uric Acid

The results of this study include the validity of the method and the performance of carbon paste electrode/MIP by potentiometry compared with the methods used in previous studies such as analysis of uric acid using HPLC method $^{5}$, analysis of uric acid using glassy carbon electrode/MIP by stripping voltammetry $^{9}$, and analysis of uric acid using carbon paste electrodes/MIP with methacrylic acid monomer by potentiometry. ${ }^{10}$ The comparison results of validity of some methods are presented in Table- 2 .

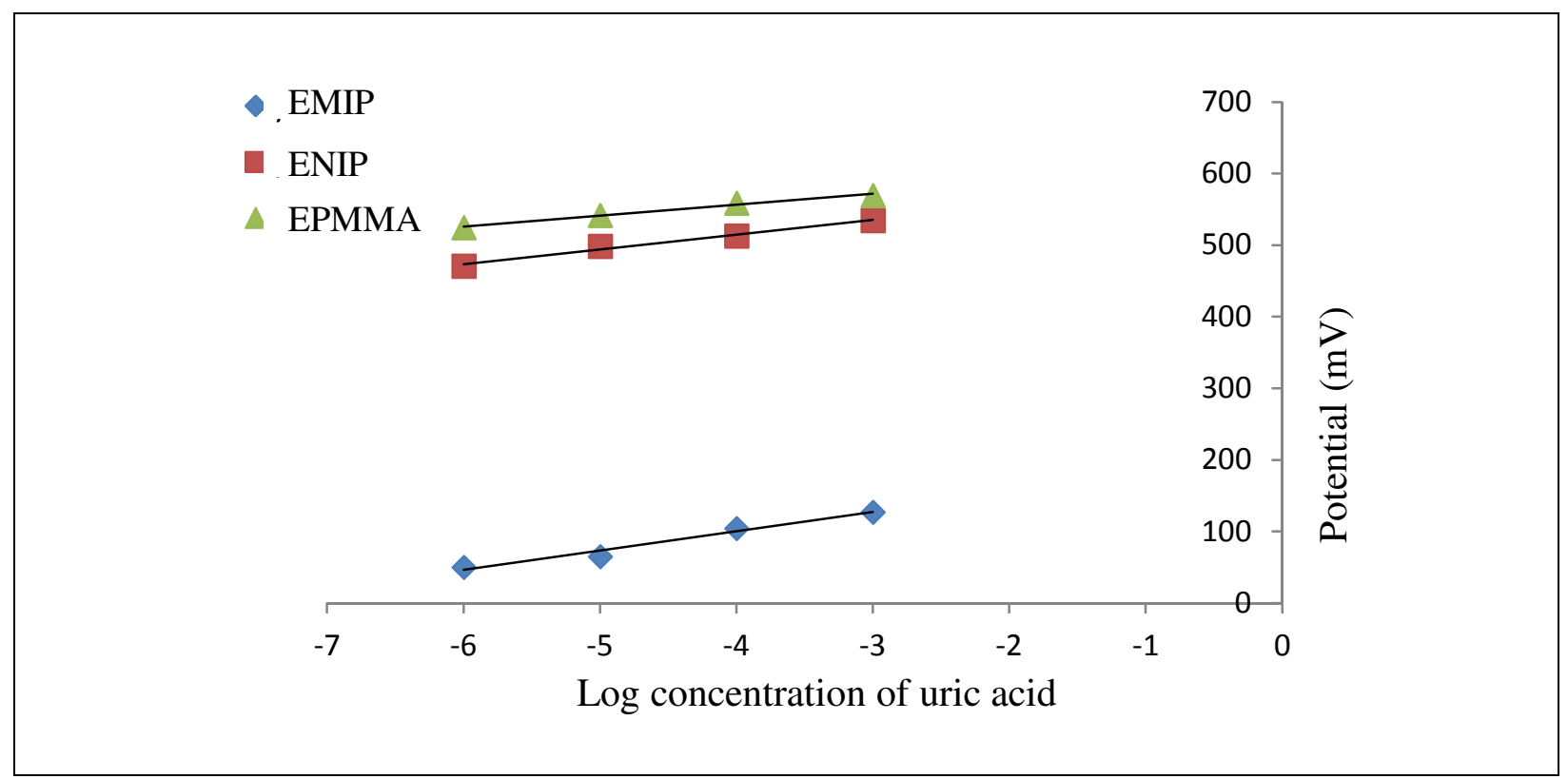

Fig.-2: The curve with relationship between log concentration of uric acid against potential from measurements results using EMIP, ENIP and EPMMA

From Table-2 it can be seen that the potentiometric method with different components of MIP has advantages in the limit of detection and lifetime of the electrode. The measurements using carbon paste electrodes/polymethyl methacrylate resulted in a lower limit of detection than measurements using carbon paste electrodes/polymethacrylic acid. The lifetime of carbon paste electrodes/polymethyl methacrylate is eight weeks (the usage is 104 times) longer than the lifetime of carbon paste electrodes/polymethacrylic acid is six weeks (the usage is 56 times). When compared with other methods can be seen that the potentiometric method has a limit of detection is higher than HPLC and voltammetry methods. But the potentiometric method has wider measurement range than HPLC and voltammetry methods.

Table-2: The comparison results of validity of some methods to analysis of uric acid

\begin{tabular}{|c|c|c|c|c|}
\hline \multirow[b]{2}{*}{ Parameter } & \multirow[b]{2}{*}{ HPLC $^{5}$} & \multirow[b]{2}{*}{ Voltammetry $^{9}$} & \multicolumn{2}{|l|}{ Potentiometry } \\
\hline & & & $\begin{array}{l}\text { Carbon paste } \\
\text { electrodes/poly } \\
\text { methacrylic acid }^{10}\end{array}$ & $\begin{array}{l}\text { Carbon paste } \\
\text { electrodes/polymethyl } \\
\text { methacrylate (this study) }\end{array}$ \\
\hline $\begin{array}{l}\text { Measurement } \\
\text { range }\end{array}$ & $\begin{array}{l}1.19 \times 10^{-6} \\
8.92 \times 10^{-5} \mathrm{M}\end{array}$ & $\begin{array}{ll}5.95 \times 10^{-9} & - \\
2.97 \times 10^{-8} \mathrm{M} & \end{array}$ & $10^{-5}-10^{-2} \mathrm{M}$ & $10^{-6}-10^{-3} \mathrm{M}$ \\
\hline Linearity & - & 0.9979 & 0.9999 & 0.9812 \\
\hline $\begin{array}{ll}\text { Limit } & \text { of } \\
\text { detection } & \end{array}$ & $6.5 \times 10^{-7} \mathrm{M}$ & $1.8 \times 10^{-9} \mathrm{M}$ & $1.35 \times 10^{-5} \mathrm{M}$ & $3.03 \times 10^{-6} \mathrm{M}$ \\
\hline
\end{tabular}


RASĀYAN J. Chem.

Vol. 10 | No. 1 |54-58 | January - March | 2017

\begin{tabular}{l|l|l|l|l}
\hline Accuracy & $96-109 \%$ & $84.75 \%$ & $96.95-102.35 \%$ & $63.9-166 \%$ \\
\hline Precision & $6.17-6.25 \%$ & $0.49-7.83 \%$ & $2.01-14.52 \%$ & $1.36-2.03 \%$ \\
\hline Selectivity & - & $\begin{array}{l}\text { More selective } \\
\text { against uric acid } \\
\text { rather than } \\
\text { ascorbic acid }\end{array}$ & $\begin{array}{l}\text { More selective against } \\
\text { uric acid rather than } \\
\text { urea }\end{array}$ & $\begin{array}{l}\text { More selective against uric } \\
\text { acid rather than urea }\end{array}$ \\
\hline Lifetime & - & - & $\begin{array}{l}\text { Six weeks (the usage is } \\
56 \text { times) }\end{array}$ & $\begin{array}{l}\text { Eight weeks (the usage is } \\
104 \text { times) }\end{array}$ \\
\hline
\end{tabular}

\section{CONCLUSION}

The measurement of uric acid with carbon paste electrodes/MIP produced Nernst factor $30.19 \mathrm{mV} / \mathrm{decade}$ in the measurements range of concentration $10^{-6}-10^{-3} \mathrm{M}$ with correlation coefficient $(r$ ) from calibration curve 0.9812 , minimum detection limit $3.03 .10^{-6} \mathrm{M}$, accuracy and coefficient of variation $(\mathrm{CV})$ of uric acid with concentration $10^{-6}-10^{-3} \mathrm{M}$ ranged from 63.9 to $166 \%$ and 1.36 to $2.03 \%$. The selectivity coefficient value was less than one, indicating that urea did not interfere with the results of the uric acid analysis. The response time of electrodes towards the uric acid with concentration $10^{-6}-10^{-3} \mathrm{M}$ was $32-60$ seconds and the electrode's lifetime was 8 weeks (the usage is 104 times).

\section{REFERENCES}

1. C.M.A. Brett and A.M. Oliveira-Brett, Journal of Solid State Electrochemistry, 15, 1487 (2011).

2. J.G. Puig and L.M. Ruilope, Journal of Hypertension, 17(7), 869 (1999).

3. W. Ren, H.Q. Luo and N.B. Li, Biosensors and Bioelectronics, 21(7), 1086 (2006).

4. J.C. Chen, H.H. Chung, C.T. Hsu, D.M. Tsai, A.S. Kumar and J.M. Zen, Sensors and Actuators BChemical, 110(2), 364 (2005).

5. S.K. George, M.T. Dipu, U.R. Mehra, P. Singh, A.K. Verma and J.S. Ramgaokar, Journal of Chromatography B, 832(1), 134 (2006).

6. H.S. Kusuma and M. Mahfud, Journal of Applied Research on Medicinal and Aromatic Plants, Articles in Press (2016). DOI: 10.1016/j.jarmap.2016.08.001

7. H.S. Kusuma and M. Mahfud, RSC Advances, 7(3), 1336 (2017). DOI: 10.1039/C6RA25894H

8. F. Wijayani, S. Supriyanto and Suyanto, Journal of Mathematics and Natural Sciences (in Bahasa Indonesia), 17(2), 1 (2015).

9. P.R. Arwindah, Development of uric acid sensor using glassy carbon electrode modified with molecularly imprinted polymer and anilin as monomer by stripping voltammetry (in Bahasa Indonesia), Thesis, Faculty of Science and Technology, Airlangga University, Surabaya (2010).

10. S.N. Andayani, The development of electrodes carbon paste nanoporous/MIP as uric acid sensor by potentiometry (in Bahasa Indonesia), Thesis, Faculty of Science and Technology, Airlangga University, Surabaya (2014).

[RJC-1558/2017] 